\title{
A Study on the Asymmetry in the Role of Monetary Policy by Using STR model
}

\author{
Guihuan ZHENG \\ Department of Statistics and Analysis, The People's Bank of China, Beijing 100800, China \\ E-mail:zghuan@amss.ac.cn \\ Yan SHANG \\ Academy of Mathematics and Systems Science, Chinese Academy of Sciences, Beijing 100190, China \\ Ying WU \\ Wesley J. Howe School of Technology Management, Stevens Institute of Technology, Hoboken, NJ \\ 07030, USA \\ Jue WANG \\ Academy of Mathematics and Systems Science, Chinese Academy of Sciences, Beijing 100190, China

\begin{abstract}
The effects of monetary policy on the economy show different with respect to its direction, power and the different economic cycle. That is to say, there exists asymmetry in the role of monetary policy. It's important to research this asymmetry for monetary policy making and keeping economy's steady growth In this paper, we aim to study the asymmetry in the role of monetary policy with respect to the different economic cycle. First, monetary shock is estimated by using monetary gap and output gap is calculated via HP filter method. Second, based on the monetary gap and output gap, the asymmetric impacts of monetary gap are measured by STR model. The results show that the impacts of monetary shock on economy are asymmetrical significantly. The impact of monetary policy on economy in upturn stage is larger than its impact in downturn stage.
\end{abstract}

Keywords asymmetry; monetary policy; STR model

The impacts of monetary policy on economy are related to monetary policy's direction, power and economic cycle. It's called the asymmetric effects of monetary policy in theory, the tightening monetary policy will reduce the growth of economy, while the easing monetary policy will stimulate economy. However, as for the monetary policy's tightening and easing, even if their powers are the same, they will affect the economy differently. Normally, the easing monetary policy in economic downturn cycle will play a smaller role than the tightening policy in upturn cycle.

In China, whether there exists the asymmetry in the role of monetary policy? This is an important issue closely related with macroeconomic policy-making. It's also an empirical problem that needs to be tested. In this paper, we focus on this asymmetric issue for different economic cycle.

Received December 11, 2013, accepted December 18, 2013

Supported by NSFC (No.71333014, No.71271202) 


\section{Introduction}

Before the 1930s, it was agreed that the impacts of easing and tightening monetary policy on the economy are symmetrical. Until the 1930s when the United States took place the Great Depression, people are beginning to realize that the role of monetary policy may be asymmetry During this Great Depression, the U.S. government adopted an expansionary monetary policy, but it did not play a significant role on the economic recovery, so that the Great Depression lasted until 1933.To the 1940s, the view of monetary policy's asymmetrical role began to be widely accepted.

In 1880 s, a number of researchers began to make some theoretical assumptions, and use the various models to test the monetary policy's asymmetry. They found that the impact of monetary policy is asymmetry (see [1], [2] and [3]). In China, the asymmetry of monetary policy hadn't been studied until the beginning of the 21st century. The researchers also found that the role of monetary policy in China's economic development reflected the feature of asymmetry (see [4]).

\subsection{The main form of asymmetry}

After a long research, scholars have proposed four major asymmetries in the form of monetary policy. The first kind of asymmetry is based on direction of monetary policy. The second one is related to strength of monetary shock. The third one may be found in economic cycles. The last one can be seen on the fact that whether monetary policy is expected.

\subsection{The method to measure asymmetry of monetary policy}

For measuring asymmetry of monetary policy in regard to economic cycle, we have to solve three problems. First, determine the state of monetary policy with the growth rate of money supply or define the monetary shock with money supply model. Second, measure the stages of economic cycle with output variables, such as GDP, industrial added value, output gap and so on. Third, estimate the asymmetric role of monetary policy. Some important econometric models already developed can be used to describe the asymmetric mechanism of monetary policy, such as Markov regime-switching model and threshold autoregressive model (see [5] and [6]). These non-linear models are applicable to describe measure and test the asymmetric role of monetary policy. Moreover, with the development of smooth transition regression model (STR model) in recent years, it targeted solution to this problem well. Now, STR model has become the main method of study this issue (see [7-13]).

In this paper, we establish money demand function to measure money shock, introduce HP filter method to calculate output gap, and then use STR model to measure the asymmetric effects of monetary policy shock.

\section{STR model}

The STR model is a nonlinear regression model that originated as a generalization of a switching regression model in the work of Bacon and Watts (see [14]) and developed by Teräsvirta et al (see [15]). These authors considered two regression lines and devised a model in which the transition from one line to the other is smooth. The STR models have been widely applied to macroeconomic time series and financial time series (see [16-18]). 
A two-regime STR model may be written as follow:

$$
y_{t}=\Phi_{1}^{\prime} x_{t}\left(1-G\left(s_{t} ; \gamma, c\right)\right)+\Phi_{2}^{\prime} x_{t} G\left(s_{t} ; \gamma, c\right)+\varepsilon_{t}
$$

where $x_{t}=\left(w_{t}^{\prime}, z_{t}^{\prime}\right)^{\prime}$, with $w_{t}=\left(1, y_{t-1}, \cdots, y_{t-p}\right)^{\prime}$ and $z_{t}=\left(z_{1 t}, z_{2 t}, \cdots, z_{k t}\right)^{\prime}$ is a vector of exogenous explanatory variables. $\Phi_{i}=\left(\phi_{0 i}, \varphi_{1 i}, \cdots, \varphi_{m i}\right)^{\prime}, i=1,2$ is parameter vectors, $m=p+k$, and $\varepsilon_{t}$ is a white noise error process with mean zero and $\sigma^{2}$. The so-called transition function $G\left(s_{t} ; \gamma, c\right)$ is a continuous function, bounded between zero and one, and the transition variable $s_{t}$ could be assumed but not limited to be a exogenous variable, a function of the lagged endogenous variable, that is $s_{t}=h\left(w_{t} ; \alpha\right)$ for some function $h$ which depends on the parameter vector $\alpha$, and even a liner time trend $\left(s_{t}=t\right)$.

One of the most popular applied choices for $G\left(s_{t} ; \gamma, c\right)$, which is also applied to this paper is the first-order logistic function

$$
G\left(s_{t} ; \gamma, c\right)=\frac{1}{1+\exp \left\{-\gamma\left(s_{t}-c\right)\right\}} \quad \gamma>0
$$

The resultant model is called the logistic STR (LSTR) model. In this case, the transition function changes monotonically from 0 to 1 as $s_{t}$ increases and $G(c ; \gamma, c)=0.5$. The parameter $c$ in (2) can be interpreted as the threshold between the two regimes, and the parameter $\gamma$ determines the speed at which the transition function changes as $s_{t}$ increases; the higher $\gamma$, the faster this change is. When $\gamma=0$, the transition function $G\left(s_{t} ; \gamma, c\right)=0.5$, so the STR model becomes linear. At the other end, when $\gamma \rightarrow \infty$, the transition function approaches the indicator function $I\left[s_{t}>c\right]$, defined as $I[A]=1$ if $A$ is true and $I[A]=0$, otherwise, and consequently, the change of $G\left(s_{t} ; \gamma, c\right)$ from 0 to 1 is becomes instantaneous at $s_{t}=c$. Hence, the LSTR model reduces to a two-regime threshold regression (TR) model. The LSTR model can model business cycle asymmetry conveniently whose dynamic properties are different in expansions from what they are in recessions, and the transition from one extreme regime to the other is smooth (see [15] and [19]).

In certain situations where the dynamic properties of the process is similar at both large and small values of $s_{t}$ (relative to $c$ ). It can be modelled by the exponential STR (ESTR) model, which is given by (1) with exponential function

$$
G\left(s_{t} ; \gamma, c\right)=1-\exp \left\{-\gamma\left(s_{t}-c\right)^{2}\right\} \quad \gamma>0
$$

The exponential function is symmetric around $s_{t}=c$ and has the property that $G\left(s_{t} ; \gamma, c\right) \rightarrow$ 1 both as $s_{t} \rightarrow+\infty$ and $s_{t} \rightarrow-\infty$ whereas $G\left(s_{t} ; \gamma, c\right)=0$ for $s_{t}=c$. For either $\gamma \rightarrow 0$ or $\gamma \rightarrow \infty$, the exponential function (3) approaches a constant, so the ESTR model collapses to a linear model. The ESTR model has been applied to real exchange rates successfully, motivated by the argument that the behavior of the real exchange rate depends nonlinearly on the size of the deviation from purchasing power parity (see [20-22]).

\section{Monetary shock and output gap}

\subsection{The definition of monetary shock}

Since higher economic growth requires higher growing of money supply, the level of money supply growth is not an absolute characterization of monetary policy direction indicators money supply should support the real economy monetary growth, should match with the development 
of the potential level of real economy and promote the economic running near the level of potential output.

When the economy is running above the level of potential output (that is positive output gap), the tightening monetary policy should be implemented to reduce the money supply rate. Then, the money supply less than demand produces negative monetary gap which conduct the economy back to potential rate, and curb inflation.

When the economy is running below the level of potential output (that is negative output gap), the easing monetary policy should be implemented to increase the money supply rate. Then, the money demand less than supply produces positive monetary gap which promote the economy recovery to potential rate.

Therefore, output gap will respond to the changes of monetary gap. To define monetary shock, the variable of monetary gap is more rational than the money supply growth.

\subsection{Estimation of monetary shock}

We introduce M2 as dependentatory variable, GDP as the independented variable. Based on the period of the first quarter 1992 to first quarter 2013, the long-term equilibrium model is established after logging these variables. With this model, we may measure the money demand of real economy from the perspective of monetary demand. The model is as follows:

$$
\begin{gathered}
\log (M 2)=\propto+\beta * \log (G D P)+\varepsilon, \\
\log (\overline{M 2})=\propto+\beta * \log (G D P) .
\end{gathered}
$$

According to the estimation equation, the model fitted values $\log (\overline{M 2})$ can be regarded as money demand; the actual statistics value $\log (M 2)$ is the money supply; the residual of the model $\varepsilon$ (denoted "resid") is monetary gap that is monetary shock.

\subsection{Estimation of output gap}

The output gap is estimated by filtering the logarithmic GDP series via HP filter method based on the same sample as before. The output gap is represented by 'gap', the logarithmic GDP is represented by ' $\log$ (gap)', and the filtered series is represented by ' $\log (\text { gap })_{\text {filter }}$ ':

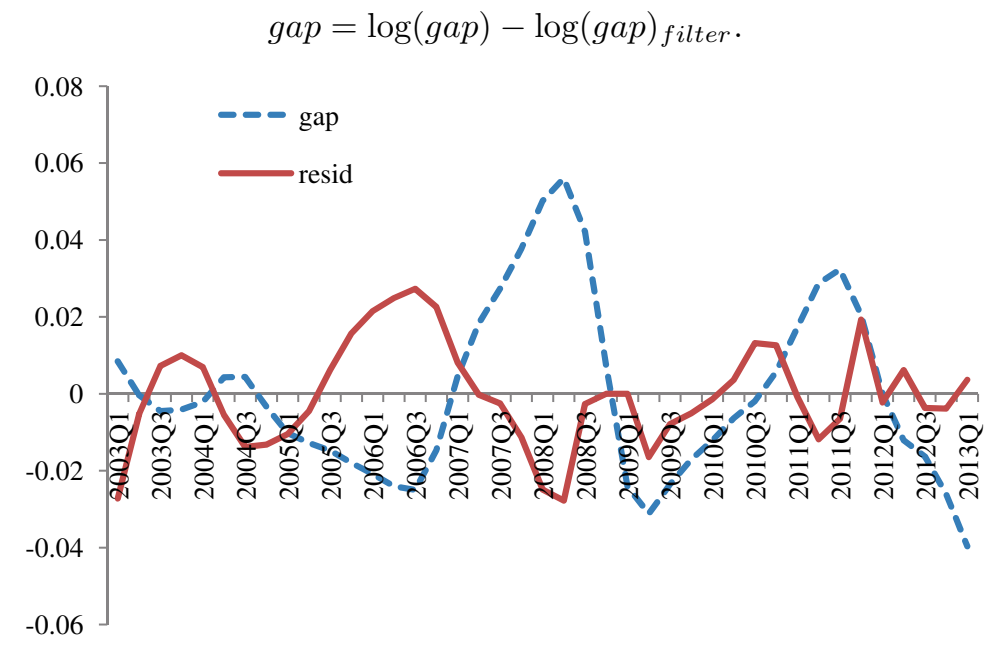

Figure 1 The time series of gap and resid 


\subsection{Relationship between monetary shock and output gap}

Seen from Chart 1, there exists negative correlation between gap and resid. Further, we use scatter diagram to test it (Figure 2). The results show that the negative correlation between gap and resid is very significant.

If gap $>0$, 'demand greater than supply' in real economy shows that economic system has maximized the potential output capacity. In this upturn stage, the tightening monetary policy will put into practice, which will produce negative monetary shock for reducing economic growth back to the potential level.

If gap $<0$, 'supply greater than demand' in real economy shows that the potential output capacity hasn't been fully explored. In this downturn stage, the easing monetary policy will put into practice, which will produce positive monetary shock for promoting economic growth close to the potential level.

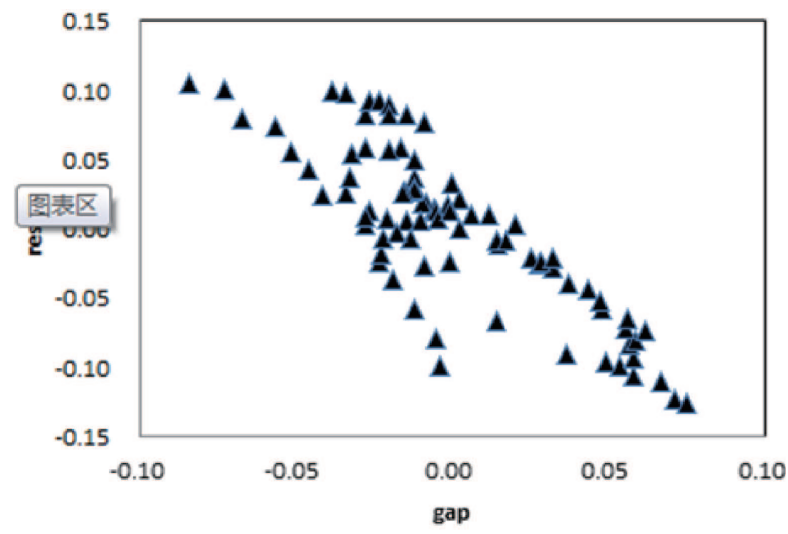

Figure 2 The scatter diagram of gap and resid

\section{To estimate the effects of monetary shock on GDP via STR model}

We establish STR model based on the same sample as before. Taking into account the lag effect of monetary policy, we introduce 'gap' as independented variable, lagged 'gap', lagged 'resid' as dependentatory variables, and lagged 'gap' as transfer variable.

According to the parameters of significance and the fit of the model test, we screen out the final selected model whose results showed in Table 1 and Figure 3.

Thus, this model can be divided into two mechanisms according to the size of the output gap. The level, whose transfer function $G\left(g a p_{t}\right)$ is equal to 0.004 , is considered as the cut-off point.

The mechanism one: gap $<0.004$. Under this mechanism, the output gap is negative or close to zero and the economy is in downturn stage, the coefficient of effects on economy from monetary shock is 0.088 .

The mechanism two: gap $_{t}>0.004$. Under this mechanism the output gap is positive and the economy is in upturn stage, the coefficient of effects on economy from monetary shock is 0.219 .

Looking at the results from the model estimation, there are significant asymmetric effects of monetary shocks on GDP. The impacts of negative monetary shock on economic grwoth in 
upturn stage are greater than those of positive shock in downturn stage.

Table 1 The estimation results for the effects of monetary shock on GDP via STR

\begin{tabular}{|c|c|c|c|c|}
\hline & coefficient & standard error & T statistics & $\mathrm{P}$ value \\
\hline$c *(1-G)$ & -0.02 & 0.002 & -0.882 & 0.190 \\
\hline $\operatorname{gap}(-1) *(1-G)$ & 0.992 & 0.090 & 10.984 & \\
\hline resid01 $(-2) *(1-G)$ & 0.088 & 0.016 & 5.513 & \\
\hline$c * G$ & -0.04 & 0.008 & -0.498 & 0.310 \\
\hline $\operatorname{gap}(-1) * G$ & 1.343 & 0.303 & 4.429 & \\
\hline resid01 $(-2) * G$ & 0.219 & 0.124 & 1.772 & 0.040 \\
\hline
\end{tabular}

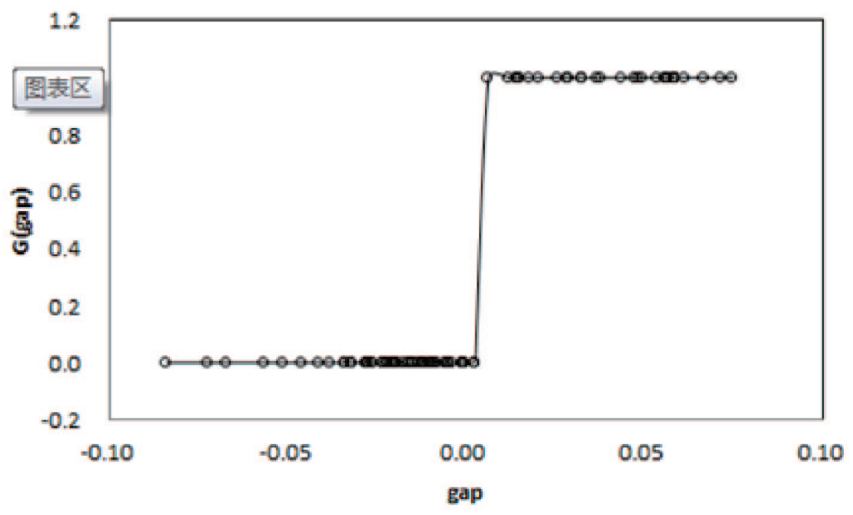

Figure 3 The transfer function chart of STR model for the effects of monetary shock on GDP

\section{To estimate the effects of monetary shock on CPI via STR model}

Based on the same sample with the previous, we establish STR model for CPI. Collect data of relative ratio with fixed base for CPI, then deal with this series with logarithmic processing and transforming by the first-order difference, denoted as 'dlcpi'. Take 'dlcpi' as independented variable, lagged 'dlcpi' and lagged 'resid' as dependentatory variables, lagged 'gap' as transfer variable.

Thus, this model can also be divided into two mechanisms according to the size of the output gap. The level, whose transfer function $G\left(\right.$ gap $\left._{t}\right)$ is equal to -0.001 is considered as the cut-off point.

The mechanism one: $\operatorname{gap}_{t}<-0.001$. Under this mechanism the output gap is negative and the economy is downturn stage, the coefficient of effects on CPI from monetary shock is 0.012 .

The mechanism two: $g a p_{t}>-0.001$. Under this mechanism the output gap is positive or close to zero, the economy is in upturn stage, the coefficient of effects on CPI from monetary shock is 0.040 .

This model estimation results show that, there are significant asymmetric effects of monetary shocks on CPI too. 
The impacts of negative monetary shock on CPI in upturn stage are greater than those of positive shock in downturn stage.

Table 2 The estimation results for the effects of monetary shock on CPI via STR

\begin{tabular}{lcccc}
\multicolumn{4}{l}{ Transfer variable: $\operatorname{gap}(-1)$} & \multicolumn{5}{l}{} \\
\hline & coefficient & standard error & T statistics & P value \\
\hline$c *(1-G)$ & 0.001 & 0.00 & 2.075 & 0.021 \\
\hline$d l c p i(-1) *(1-G)$ & 1.094 & 0.031 & 35.156 & \\
$\operatorname{resid} 01(-1) *(1-G)$ & $\mathbf{0 . 0 1 2}$ & 0.007 & 1.766 & 0.040 \\
$c * G$ & -0.001 & 0.0012 & -1.201 & 0.117 \\
$\operatorname{dlcpi}(-1) * G$ & 1.006 & 0.074 & 13.628 & \\
resid $01(-1) * G$ & $\mathbf{0 . 0 4 0}$ & 0.021 & 1.908 & 0.030 \\
\hline
\end{tabular}

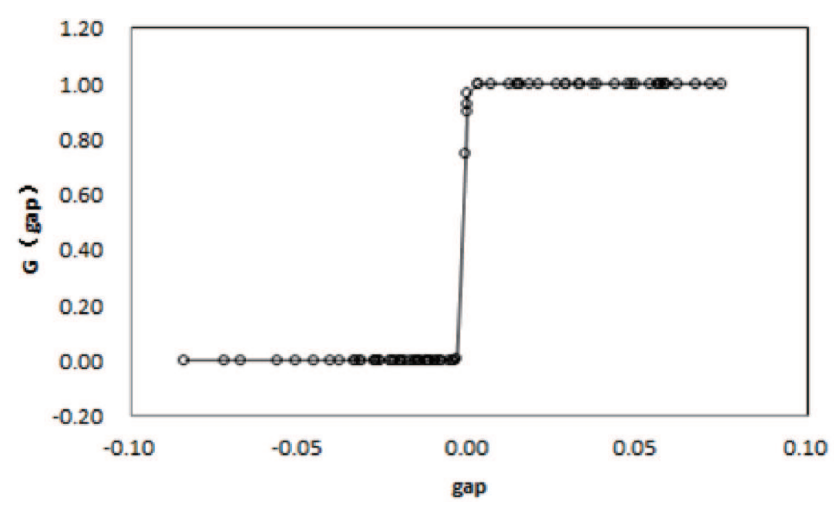

Figure 4 The transfer function chart of STR model for the effects of monetary shock on CPI

\section{Conclusions}

In this paper, define monetary gap as monetary shock to describe monetary policy, establish STR model by using output gap as transfer variable in order to research asymmetric effects of monetary policy. The results show that there exist the asymmetric influences of monetary policy on economic growth and CPI obviously. The impacts of negative monetary shock resulted by tightening policy on CPI in upturn stage are greater than those of positive shock resulted by easing policy in downturn stage clearly. Consequently, with the adjustment of monetary policy, the proactive fiscal policy should be adopted to stimulate the demand of investment and consume in downturn stage.

As is we all known, the asymmetric effects of monetary policy may be seen not only in different economic cycles, but also in the direction and power of monetary policy. Thus, the issue to study asymmetry from multi-dimension via multi-mechanisms STR modeling should be researched further.

\section{References}

[1] De L J, Summers L. How does macroeconomic policy affect output. Brookings Papers on Economic Activity, 1988, 2: 433-480. 
[2] Cover J. Asymmetric effects of positive and negative money supply shocks. Quarterly Journal of Economics, 1992, 107(4): 1261-1282.

[3] Karras G. Are the output effects of monetary policy asymmetric? Evidence from a sample of European countries. Oxford Bulletin of Economics and Statistics, 1996, 58: 267-278.

[4] Liu J Q. Studies of the effectiveness and asymmetry of monetary policy in China's economy. Management World, 2002, 3: 43-59.

[5] Zhang X Y, Liu J Q. Testing for the asymmetry of monetary policy's effects based on the menu cost models. Journal of Central South University (Social Science), 2009, 15(5): 647-652.

[6] Ouyang Z G. The nonlinear dynamics of interest rate in China and its effect on monetary policy. Statistical Research, 2009, 26(4): 33-39.

[7] Bec F, Salem M B, Collard F. Nonlinear economic policies: Pitfalls in the lucas critique empirical counterpart. Working Paper, University de Cergy-Poontoise, 2000.

[8] Kesriyeli M, Osborn D R, Sensier M. Nonlinear and structure change in interest reaction function for the US, UK and Germany. Discussion Paper Series of the University of Manchester, 2004.

[9] Martin C, Milas C. Modeling monetary policy: Inflation targeting in practice. Economica, 2004, 71: 209221.

[10] Zhao J W, Ming J. Empirical study on the asymmetry of the effect of monetary policy operation of China's center bank. Economic Research Journal, 2005, 2: 26-34.

[11] Zheng T G, Liu J Q. Empirical analysis of asymmetric money-output causality China: Based on the smooth transition vector error-correction model. Economic Research Journal, 2008, 1: 33-45.

[12] Bruggemann R, Riedel J. Nonlinear interest rate reaction functions for the UK. Working Paper, www.unigraz.at/socialpolitic/papers/Brueggemann.pdf, 2008.

[13] Liu J Q, Duo J L, Li N. Asymmetric effects of China's monetary policy: Evidence from a nonlinear VAR model. Chinese Journal of Management Science, 2009, 17(3): 47-55.

[14] Bacon D W, Watts D G. Estimating the transition between two intersecting straight lines. Biometrika, 1971, 58(3): 525-534.

[15] Teräsvirta T, Anderson H M. Characterizing nonlinearities in business cycles using smooth transition autoregressive models. Journal of Applied Econometrics, 1992, 7: 119-136.

[16] Skalin J, Teräsvirta T. Modelling asymmetries and moving equilibria in unemployment rates. Macroeconomic Dynamics, 2002, 6(2): 202-241.

[17] McMillan D G. Non-linear predictability of stock market returns: Evidence from nonparametric and threshold models. International Review of Economics \& Finance, 2001, 10(4): 353-368.

[18] Sarantis N. Nonlinearities, cyclical behaviour and predictability in stock market: International evidence. International Journal of Forecasting, 2001, 17(3): 459-482.

[19] Skalin J, Teräsvirta T. Another look at Swedish business cycles, 1861-1988. Journal of Applied Econometrics, 1999, 14(4): 359-378.

[20] Michael P, Nobay A R, Peel D A. Transaction costs and nonlinear adjustment in real exchange rates: An empirical investigation. Journal of Political Economy, 1997, 105(4): 862-879.

[21] Sarantis N. Modelling nonlinearities in real effective exchange rates. Journal of International Money and Finance, 1999, 18(1): 27-45.

[22] Taylor M P, Peel D A, Sarno L. Nonlinear mean-reversion in real exchange rates: Towards a solution to the purchasing power parity puzzles. International Economic Review, 2001, 42(4): 1015-1042.

[23] Kandil M. Asymmetric nominal flexibility and economic fluctuations. Southern Economic Journal, 1995, 61: $674-695$. 